\title{
Estratégias Digitais de Combate aos Impactos da Pandemia Covid-19 no Contexto Empresarial
}

\author{
Digital Strategies to Combat the Impacts of the Covid-19 Pandemic in the
}

Business Context

\section{RESUMO}

\begin{abstract}
A pandemia Covid-19 é considerada uma crise sem precedentes, pelo seu caráter atípico e porque se arrastou ao longo do tempo. Metaforicamente, considera-se um evento cisne negro, ou seja, um evento surpreendente e imprevisível de grande significado e graves consequências que alteram drasticamente o ambiente político e económico. Como resultado das alterações existentes, as empresas tiveram de se adaptar a um novo contexto, a um novo consumidor e a uma nova forma de operar. O presente estudo surge orientado para a exploração das principais estratégias digitais levadas a cabo pelas empresas para minorar/explorar os efeitos da situação pandémica atual. Para o efeito, propõe-se uma metodologia qualitativa, baseada em 7 entrevistas semiestruturadas a gestores de empresas que atuaram durante a pandemia e no contexto digital, de modo a conhecer os principais impactos da pandemia e estratégias digitais utilizadas para os minorar/explorar. O estudo aborda as estratégias digitais que se revelaram bemsucedidas para gerir a situação pandémica nas empresas entrevistadas, destacando-se o foco no cliente, o foco no serviço, o desenvolvimento de parcerias, a criação de novos produtos e serviços e a adoção de medidas socialmente responsáveis. Este estudo apresenta as principais estratégias digitais levadas a cabo pelas empresas em estudo num contexto de medo e incerteza. É um contributo valioso a nível empresarial, não só para o período pandémico em questão, mas também para crises futuras.
\end{abstract}

Palavras-chave: Covid-19; estratégias digitais; marketing digital; impactos pandémicos

\footnotetext{
* Instituto Superior de Contabilidade e Adminisração do Porto, Instituto Politécnico do Porto, Portugal. E-Mail: joanaaasantos_@hotmail.com

** Instituto Superior de Contabilidade e Adminisração do Porto, Instituto Politécnico do Porto, Portugal. E-Mail: analima@iscap.ipp.pt
} 


\begin{abstract}
The Covid-19 pandemic is considered an unprecedented crisis, due to its atypical character and because it has dragged on over time. Metaphorically, it is considered a black swan event, that is, a surprising and unpredictable event of great significance and serious consequences that drastically alter the political and economic environment. As a result of the existing changes, companies had to adapt to a new context, a new consumer and a new way of operating. This study is aimed at exploring the main digital strategies carried out by companies to mitigate/exploit the effects of the current pandemic situation. For this purpose, a qualitative methodology is proposed, based on $7 \mathrm{semi}$ structured interviews with managers of companies that acted during the pandemic and in the digital context, in order to know the main impacts of the pandemic and digital strategies used to minimize/explore them. The study approaches the digital strategies that have proven successful to manage the pandemic situation in the interviewed companies, highlighting the focus on the customer, the focus on service, the development of partnerships, the creation of new products and services and the adoption of socially responsible measures. This study presents the main digital guidelines carried out by the companies under study in a context of fear and uncertainty. It is a valuable contribution at the business level, not only for the pandemic period in question, but also for future crises.
\end{abstract}

Keywords: Covid-19; digital strategies; digital marketing; pandemic impacts

Received on: $2021 / 09 / 03$

Approved on: 2022/01/14

Evaluated by a double blind review system

\title{
1. INTRODUÇÃO
}

A Covid-19 é uma doença infeciosa, que surgiu na China em dezembro de 2019 e alastrou-se aos restantes países, já sendo considerada um dos maiores desafios sanitários mundiais do século (Barreto et al., 2020). Medidas como a quarentena, isolamento social e restrições à movimentação das pessoas afiguraram-se, na grande maioria dos países, como as melhores estratégias de combate à proliferação da doença (Croda et al., 2020). 
Apesar da tragédia humanitária causada pela pandemia, esta também provocou impactos significativos a nível social, económico cultural e político (Winston, 2020).

Desta forma, as empresas tiveram de se adaptar às rápidas mudanças do ambiente de marketing, a um novo consumidor e a uma nova forma de operar, levando-as o a definirem, forçosamente, novas estratégias. O consumo online, como esperado, cresceu exponencialmente, o que se refletiu em vantagens para as empresas, mas também, em desafios e problemas nunca antes vividos, que tiveram de colmatar, através de um conjunto de ágeis e inovadoras estratégias. Este é talvez o evento mais transformador e desafiante da história das empresas.

Tratando-se de uma temática atual e ainda pouco explorada, a literatura não é elucidativa acerca das respostas empresariais e no contexto digital para situações tão atípicas como uma pandemia mundial. Em virtude disto, define-se como objetivo principal da investigação explorar as principais estratégias digitais levadas a cabo para minorar/explorar os efeitos da situação pandémica atual.

$\mathrm{O}$ artigo inicia com uma abordagem teórica, seguida das opções metodológicas que darão forma ao objetivo do estudo, a análise de dados e discussão e, por fim, apresentase as conclusões e implicações, bem como, limitações e investigação futura.

\section{REVISÃO DA LITERATURA}

\subsection{A Covid-19 e o seu impacto no contexto económico e empresarial}

Os impactos da pandemia Covid-19 não terão precedentes desde a Grande Depressão de 1930 (Euronews, 2020), representando uma das mudanças ambientais mais significativas na história do marketing moderno (He \& Harris, 2020).

$\mathrm{Na}$ verdade, os efeitos do Covid-19 são diferentes mediante a natureza dos produtos, o que significa que o impacto em alguns produtos - e, consequentemente, empresas pode ser positivo ou negativo. Enquanto algumas empresas estão a lutar pela sua sobrevivência, principalmente as relacionadas aos serviços, outras estão a prosperar. Esta realidade acontece, sobretudo, em empresas baseadas na internet, como entretenimento online, entrega de comida, compras online, educação online e soluções de trabalho remoto. Outros setores que também apresentam resultados positivos são os relacionados com a saúde e higiene (Donthu \& Gustafsson, 2020). 


\subsection{O meio digital como resposta aos desafios empresariais durante a pandemia}

Durante a pandemia, as inovações digitais rapidamente se tornaram os pilares da vida pessoal e profissional (Panigutti, Perotti \& Pedreschi, 2020), sobretudo, pela possibilidade de acesso a qualquer hora, em qualquer lugar e de variados meios.

Os graves desafios globais da pandemia podem ser enfrentados através de uma grande variedade de tecnologias digitais, como internet of things, inteligência artificial e análise do big data (Donthu \& Gustafsson, 2020).

Embora o uso da tecnologia não possa impedir a propagação da pandemia, pode instruir, alertar e permitir que a situação reduza significativamente os seus efeitos nefastos, permitindo a interação entre pessoas (Kodama, 2020).

É neste contexto que as tecnologias digitais surgem como uma resposta estratégica, flexível e adaptável, que permitem uma atualização rápida da estratégia do negócio e oferecem uma alternativa às restrições impostas (Shiffman e Shawar, 2020). A pandemia pode ser considerada o acelerador para os que têm sido avessos às tecnologias, se renderem às mesmas (Kim, 2020).

\subsection{A resposta das empresas}

A pandemia é o evento mais revolucionário e transformador que as empresas têm memória e apesar de ter começado como um problema de saúde pública, rapidamente criou problemas a nível empresarial (Stewart, 2021). Os líderes e gestores lidam com uma situação sem precedentes, caraterizada pela falta de informação ou por esta ser incompleta e imprecisa, torna-se fulcral que tomem decisões críticas rapidamente de forma eficiente e eficaz em todos os níveis de tomada de decisão - estratégico, tático e operacional. É neste contexto que as empresas começaram a adotar planos de contingência para fazer fase a esta situação (Dwivedi et al., 2020; Castro et al., 2020).

Para muitas empresas, esta situação revelou riscos até então não percebidos, como a dependência de um único canal de aquisição, ausência de um plano consistente para o relacionamento e retenção de clientes e a falta de ferramentas e processos adaptados aos meios digitais. A pandemia demonstrou que as empresas precisam se adaptar para sobreviver, evoluir e garantir a sustentabilidade a longo prazo (Outmarketing, 2020). O isolamento social tem tido um grande impacto no volume de vendas, visto que os consumidores também precisaram se adaptar às mudanças advindas da crise (Batista et al., 2020). 
$\mathrm{Na}$ verdade, métricas pós-pandémicas, padronizadas e aparentemente incontestáveis, como valor de vida do cliente, serão, provavelmente, questionadas de forma crítica. Embora pareça pouco provável que tais métricas sejam totalmente desconsideradas, parece provável que os profissionais de marketing irão adaptar e complementar tais métricas (He \& Harris, 2020).

Sendo uma crise global, não existem respostas certas nem estratégias simples para enfrentar um cenário tão incerto (Castro et al, 2020). Enquanto os estrategas há muito tempo que defendem a agilidade na formulação de estratégias, a velocidade relâmpago da disseminação da Covid-19 exigiu que as organizações desenvolvessem tal agilidade empresarial a ponto de ser considerada híper mobilidade (He \& Harris, 2020), sendo as empresas pressionadas a criar produtos/serviços e se adaptar radicalmente para permanecerem visíveis, ágeis e produtivas (Kim, 2020).

Para as empresas se posicionarem no "novo normal" devem melhorar a sua capacidade de resiliência operacional, acelerar a digitalização da cadeira de valor, aumentar rapidamente a transparência das despesas operacionais e de capital, priorizar o teletrabalho, reinventar operações sustentáveis, garantir a competitividade, estudar o consumidor e adotar modelos de negócio que tenham em consideração eventos e cenários de interrupção (Castro et al., 2020; Verma \& Gustafsson, 2020).

São diversos os autores que defendem o estabelecimento de parcerias para fazer face aos impactos da Covid-19. Na visão de Seetharaman (2020), as empresas devem procurar posições estratégicas e parceiros no novo ecossistema para se manterem competitivas. Crick \& Crick (2020), acrescentam que a coopetição pode ser uma estratégia de marketing B2B eficaz na pandemia, tendo o potencial de beneficiar as organizações envolvidas em tais parcerias, bem como os clientes e outras as partes interessadas.

Think Google (2020) lançou um guia chamado "5 approaches that are helping brands and people in Brazil during Covid-19 que tem como objetivo fornecer recursos e soluções para as empresas comunicarem com o seu público durante a pandemia. As estratégias e modelos passam, sobretudo, por ajudar, quanto possível, por exemplo, na produção de álcool gel e protetores faciais para doar; condições especiais para clientes, torna-se essencial perceber o que é mais relevante para o cliente num momento de crise e, se possível, flexibilizar algumas condições, por exemplo, oferecer um horário mais alargado exclusivo para pessoas de risco ou novas políticas de cancelamento de reservas; 
adaptação do modelo de negócio, por exemplo, entrega sem contacto físico e prestação de serviços online; ações de impacto social, como, por exemplo, ampliar os prazos de pagamento; mudança de tom, adequando-o à pandemia, reforçando a ideia de que devemos evitar o contacto social, mas que nos podemos manter fortes e unidos neste momento.

Também, Koholi et al. (2020) destacam um conjunto de desafios na área das vendas, marketing e logística. Quanto às vendas sugere-se que se reinvente a experiência de compra e priorização dos recursos digitais. Ao nível do marketing, fazer uma reflexão no orçamento, apostar na presença digital e compreender novos hábitos de compra e fidelidade, garantindo um atendimento personalizado, de confiança e fornecendo incentivos para primeiras compras. Relativamente à logística, deve-se compreender e adaptar a novas necessidades, nomeadamente de segurança.

Em síntese, é vital que as empresas se lembrem que a atitude que assumem durante uma crise influencia a perceção da sociedade (Salvador \& Ikeda, 2018). Muitas empresas têm um propósito social e um conjunto de valores que indicam o quanto estimam os seus clientes e funcionários. Este é o momento para cumprirem esse compromisso (Donthu \& Gustafsson, 2020). Por meio de uma comunicação clara e adaptada ao contexto, as empresas podem garantir a confiança do consumidor, concentrando-se em ações que demonstrem como os seus produtos e serviços podem ajudá-los durante a pandemia, expressando empatia e apoio às pessoas mais afetadas (Batista et al., 2020; Vapiwala, 2020). O vínculo estabelecido entre a marca e o consumidor durante uma era de crise pode ser mais significativo e duradouro do que em tempos de "paz" (He \& Harris, 2020). Pelo contrário, o oportunismo de alguns retalhistas em aumentar o preço de produtos essenciais, como desinfetantes, possivelmente levará a um ressentimento relutante, mesmo depois da normalidade ser restaurada (Pantano et al., 2020).

\section{METODOLOGIA}

\subsection{Tipo de estudo}

De forma a conseguir responder à questão de investigação do estudo "Quais as estratégias digitais levadas a cabo pelas empresas para explorar/minorar os efeitos da pandemia Covid-19?", escolheu-se uma metodologia qualitativa. De acordo com Bryman e Bell (2011), a metodologia qualitativa é a indicada quando se pretende estudar problemas pouco conhecidos ou entender um fenómeno como um todo. $\mathrm{O}$ 
objetivo é estudar o comportamento e atividade das pessoas e organizações de forma a desenvolver conceitos, ideias e entendimentos a partir de padrões encontrados nos dados recolhidos (Sousa \& Batista, 2011).

\subsection{Instrumento de recolha de dados}

O instrumento de recolha de dados aplicado foi a entrevista semiestruturada que visa determinar as respostas subjetivas em relação a uma situação ou fenómeno particular que os entrevistados tenham experienciado (Silverman, 2011).

Através da entrevista semiestruturada, pretende-se explorar as principais estratégias digitais levadas a cabo pelas empresas para fazer face à situação pandémica, permitindo que o investigador siga um conjunto de questões previamente definidas, presentes no guião da entrevista, mas num contexto mais informal e flexível. Assim, a entrevista pode levar à recolha de informações de uma forma mais livre e flexível, favorecendo a espontaneidade nas respostas e possibilita a clarificação de respostas visto que existe diálogo entre o entrevistador e o entrevistado (Yin, 2014).

As entrevistas devem assentar num guião prévio que norteie os objetivos do estudo. Para a construção do guião sugere-se elaborar perguntas de acordo com o tema, os objetivos do estudo e as expectativas do entrevistador, construir perguntas variadas e abertas, evitando influenciar as respostas e procurando alternativas para eventuais fugas ao tema, adequar as perguntas ao entrevistado e à situação e estabelecer o número de perguntas e proceder à sua ordenação (Flick, 2005).

Para a realização das entrevistas, foi criado um guião, que resultou da revisão da literatura, com questões centradas na estratégia digital das empresas durante a pandemia Covid-19. A primeira parte do guião pretende responder a questões relacionadas com dados sociodemográficos da empresa. A segunda parte, por sua vez, pretende conhecer a empresa de uma forma mais estratégica, nomeadamente o seu público-alvo e se existiram alterações neste provocadas pela pandemia, a presença e importância das redes sociais, o e-commerce e a sua importância, a relação com o cliente no meio digital, o orçamento destinado ao digital e as alterações provocadas pela pandemia. A terceira parte, é mais focada na pandemia Covid-19 e nas estratégias implementadas, nomeadamente a forma como a crise pandémica afetou a empresa, as estratégias digitais levadas a cabo para minorar/explorar os efeitos da pandemia, o desenvolvimento de parcerias (Crick \& Crick, 2020; Seetharaman, 2020), a criação de novos produtos/serviços (Kim, 2020), a adoção de medidas socialmente responsáveis (Batista 
et al., 2020; Donthu \& Gustafsson, 2020; He \& Harris, 2020; Pantano et al., 2020; Salvador \& Ikeda, 2018) e a perceção de alterações no comportamento do consumidor (Donthu \& Gustafsson, 2020).

Procedeu-se à testagem do guião com um ator externo à investigação, de modo a verificar-se a adequação do guião à entrevista e a observar-se eventuais ajustes.

A recolha de dados foi feita através do contacto com empresas através do Linkedin e email da empresa entre os meses de março e abril de 2021. Numa primeira fase, foi explicado o objetivo da investigação e garantida a anonimização da empresa, caso fosse pretendido, o cumprimento de questões éticas, bem como a possibilidade de desistência a qualquer momento. Quanto a questões mais sensíveis, esclareceu-se o pleno direito da não resposta.

As entrevistas foram gravadas com consentimento dos entrevistados de modo a facilitar a concentração no discurso, transcritas e submetidas a uma análise de conteúdo.

\subsection{Amostra}

O tipo de amostragem que irá dar forma ao estudo é a amostragem intencional. A amostragem intencional faz parte do grupo de amostragens não probabilísticas e ocorre quando os elementos selecionados são escolhidos pelo investigador. Este tipo de amostragem pode gerar bons resultados, desde que haja bons critérios de julgamento, tornando o trabalho mais rico em termos qualitativos. A amostra será constituída por profissionais de marketing de empresas portuguesas, que exerceram durante a pandemia e tomaram decisões ao nível estratégico e digital (Dias, 2009).

Os critérios de seleção da amostra foram baseados em princípios de homogeneidade, ou seja, empresas que se viram, de alguma forma afetadas pela pandemia e cujo meio digital tem grande relevância no negócio. Por sua vez, também se usou critérios intencionais, baseados no julgamento dos pesquisadores, ou seja, quando se acreditava que determinada empresa iria contribuir com informações relevantes para a investigação, tentando, também, diversificar a amostra com áreas de negócio distintas, nomeadamente moda e acessórios, decoração, turismo e soluções digitais.

A realização de entrevistas só deve encerrar quando se atingir uma saturação teórica, ou seja, quando o acréscimo de novas informações deixa de ser necessário, pois não altera a compreensão do fenómeno estudado (Guest, Bunce, \& Johnson, 2006).

\subsection{Procedimentos de análise de dados}

A análise de conteúdo foi o procedimento escolhido para analisar os dados da 
investigação. É um conjunto de técnicas de análise de comunicação que visam obter, por meio de procedimentos sistemáticos e objetivos de descrição do conteúdo das mensagens, indicadores que permitam a inferência de conhecimentos relativos às condições de produção/receção (variáveis inferidas) destas mensagens (Bardin, 2011). Procedeu-se à codificação para reunir todos os materiais acerca de um determinado tema, ideia ou tópico. A codificação é o processo de análise de dados qualitativos de texto, que visa separá-los, analisá-los e reuni-los de forma significativa (Creswell, 2015). As entrevistas individuais em profundidade foram transcritas e foram codificadas segundo os seguintes temas: alterações do público-alvo, importância das redes sociais, importância do meio digital como ponto de venda, relacionamento com o cliente no meio digital, alterações no orçamento de marketing digital devido à pandemia, como a pandemia afetou a empresa, estratégias digitais para minorar/explorar os efeitos da pandemia, desenvolvimento de parcerias durante o período pandémico, diferenças percecionadas no consumidor, criação de produtos/serviços e, por fim, responsabilidade social corporativa.

\section{ANÁLISE DE DADOS E DISCUSSÃO DE RESULTADOS}

\subsection{Caraterização da amostra}

A amostra é constituída por sete profissionais de marketing de empresas portuguesas, que exerceram funções durante a pandemia Covid-19 e tomaram decisões ao nível estratégico e no contexto digital: Country Marketing Manager do IKEA, Marketing, Growth \& Performance Team Leader de uma empresa anonimizada de marketplace generalista, fundador da The Florist, CEO e Co-Founder da Pleez, Diretora de Marketing e Comunicação da Odisseias, E-commerce Marketing Director da La Redoute e E-commerce e Digital Marketing Manager da Eugénio Campos.

\subsection{Análise de conteúdo}

\subsubsection{Alterações no público-alvo}

Ao nível do público-alvo a maioria das empresas entrevistadas considera que existiram modificações, sobretudo, uma vez que o consumidor mudou, inevitavelmente as suas rotinas e passou a ter novas necessidades e porque com a grande maioria do comércio físico fechado, o meio digital ganhou mais importância.

“As necessidades na casa mudaram. A casa, de repente, tornou-se um escritório, sala de aulas, ginásio... Tivemos muitos targets novos, a importância da casa 
mudou na vida das pessoas”. Country Marketing Manager IKEA

“A categoria de mercado e gourmet, que é uma parte de supermercado, bebidas, conservas, massas, etc., até março de 2020 era uma categoria que não tinha grande representatividade em termos de negócio e acabou por se tornar uma das categorias principais. Foi sem dúvida a categoria que conseguimos exponenciar mais durante a pandemia”. Marketing, Growth \& Performance Team Leader Empresa Marketplace generalista.

"Temos um volume de crescimento de novo cliente e novo utilizador. $O$ consumidor teve de encontrar formas de consumo diferentes. O que vejo nas últimas semanas é um crescer muito grande do alimentar." E-commerce Marketing Director La Redoute.

\subsubsection{Importância das redes sociais}

Quanto à importância das redes sociais, a totalidade dos entrevistados considera que a presença da empresa nas redes sociais é de extrema importância, sobretudo, pela proximidade, rapidez e visibilidade que estas plataformas oferecem.

"É uma forma de estarmos mais próximos das pessoas, de interagirmos com elas, medirmos o impacto das nossas ações junto delas, medir a satisfação do cliente. Permite-nos ter uma visão real da vida das pessoas." Country Marketing Manager IKEA.

"Usamos principalmente para criar awareness e colocar a marca em outros nichos que ainda não tínhamos chegado. Queremos criar uma comunidade específica em cada uma das redes sociais.” Marketing, Growth \& Performance Team Leader Empresa Marketplace generalista.

“Queremos ficar na memória das pessoas, se formos aparecendo não caímos no esquecimento e, por isso, é muito importante termos visibilidade e o facto de estarmos associados a algumas pessoas dá-nos credibilidade e isso é muito importante nas redes sociais." Fundador The Florist.

"É uma forma de estarmos mais perto dos nossos clientes, comunicarmos ofertas, entretê-los, inspirá-los a fazer da vida uma verdadeira experiência." Diretora de Marketing e Comunicação Odisseias.

\subsubsection{Relacionamento com o cliente no meio digital}

No que diz respeito ao relacionamento com o cliente no meio digital, a maioria dos entrevistados considera que este meio tem imensas vantagens e que é uma forma de ter 
feedback direto do cliente, criar uma relação de valor com este e proporcionar a melhor experiência possível.

"Sempre fomos à distância, mas temos um foco enorme no cliente. Temos todas as plataformas disponíveis. Por exemplo, recebemos um prémio no Portal da Queixa, porque temos as queixas todas a 100\%, o que pretendemos é que quem compra tenha uma experiência de compra excelente e que saiba que é uma empresa séria onde possa recomprar sem problema nenhum e que atrás do mundo digital existem pessoas". E-commerce Marketing Director La Redoute "Tem uma vantagem muito própria, que é o conseguirmos, efetivamente, ter um feedback direto do cliente, perceber as suas frustrações e também a parte positiva, claro. Foi essencial este ano, o apoio ao cliente na área digital é um grande suporte, quando é bem trabalhado, para melhorar toda a rede e estrutura comercial da empresa, seja no tradicional ou no digital, porque a maioria das dores e frustrações que possam existir no digital são as mesmas da venda tradicional." E-commerce e Digital Marketing Manager Eugénio Campos.

\subsubsection{Alterações no orçamento de marketing digital devido à pandemia Covid-19}

Ao nível do orçamento de marketing digital da empresa dos entrevistados, de facto, considera-se que a grande maioria, investe, significativamente. Com a pandemia, notase, também, que grande parte das empresas apostaram mais no meio digital.

"Aumentou bastante, principalmente devido aos patrocínios e ofertas que fizemos. Nunca pagamos a nenhum influencer, mas temos o custo do bouquet que oferecemos. Também começamos a trabalhar com uma empresa de gestão de redes sociais”. Fundador The Florist.

" $O$ digital foi o foco das empresas, onde poderiam ir buscar uma mais-valia para um ano extremamente prejudicial, só existia o digital e o foco no investimento foi quase todo para a área digital”. E-commerce e Digital Marketing Manager Eugénio Campos.

\subsubsection{Como a pandemia Covid-19 afetou a empresa}

A pandemia Covid-19, claramente, acabou por afetar todas as empresas entrevistadas, sobretudo, numa primeira fase em que não se sabia bem o que estava a acontecer e quais seriam as consequências. Por um lado, muitas das empresas entrevistadas conseguem ver um lado positivo da crise, outras, as mais relacionadas a serviços e turismo, veem-se mais afetadas. 
“Afetou-nos um bocadinho, mas gostamos de ver o lado positivo das coisas. $\mathrm{Na}$ altura não sabíamos a gravidade do vírus e o que poderia provocar na sociedade. Decidimos de imediato proteger os colaborados e implementar medidas de segurança, para garantir que as pessoas se sentiam bem a desempenhar o seu trabalho. Investimos em formações e saúde mental, esta fluidez de trabalhar em casa tem os seus perigos. Também recebemos uma explosão de necessidades e, infelizmente, não tínhamos capacidade de dar resposta a todas, pode ter gerado alguma insatisfação em alguns momentos do processo, como não haver stock de artigos ou estes demorarem mais do que esperado. Obviamente que perdemos financeiramente, mas quando olhamos para o ano, a quebra foi muito pequena face ao cenário em que vivemos, tivemos as lojas fechadas muitos meses.” Country Marketing Manager IKEA.

"Em termos de negócio foi muito bom, conseguimos tirar vantagem de muitas pessoas começarem a comprar online e tivemos a agilidade e facilidade de nos colocarmos muito rápido no mercado para destacar o que era importante na altura, como bens essenciais de supermercado." Marketing, Growth \& Performance Team Leader Empresa Marketplace generalista.

“Quanto às vendas, tudo ok. Ao nível dos clientes, notávamos ao início algum medo. A parte mais complicada de gerir foi os chamados dias grandes, como o Dia dos Namorados e o Dia da Mãe, por exemplo, em que acabamos por necessitar de mais recursos humanos e durante a pandemia, tivemos de limitar as pessoas que estavam a ajudar-nos para estarmos todos seguros. No Dia dos Namorados, por exemplo, tivemos menos ajuda e muito mais encomendas". Fundador The Florist.

"No primeiro confinamento, o foco era inovar, fazer diferente, melhorar. Neste, segundo, é só sobreviver.” CEO \& Co-Founder Pleez.

"Fomos muito afetados a nível de vendas. Felizmente, as nossas experiências têm a validade de 3 anos e, por isso, as pessoas continuaram a adquirir para oferta." Diretora de Marketing e Comunicação Odisseias.

"No início da pandemia, em março e abril, percebemos que a confiança do consumidor andou muito tremida, houve um medo instalado na sociedade. A partir da segunda quinzena de abril, houve, claramente, um retomar da atividade e crescimento. Para nós, teve um efeito positivo, porque o Covid foi 
quase o evangelizador do e-commerce, foi aquele incentivo ao consumidor." Ecommerce Marketing Director La Redoute.

“A nível digital tudo foi melhorado. Todas as relações e todo o ambiente em volta do comércio eletrónico teve quase um upgrade. Foi um ano de teste, todas as dinâmicas foram aperfeiçoadas e melhoradas, sem exceção, todas cresceram." E-commerce e Digital Marketing Manager Eugénio Campos.

\subsubsection{Estratégias digitais para minorar/explorar os efeitos da pandemia Covid-19}

Ao nível das estratégias digitais para colmatar e, até mesmo, explorar os efeitos da pandemia, notou-se muito o foco no cliente, o tentar compreender e demonstrar que estávamos todos juntos nesta fase complicada e o foco no serviço, como as entregas gratuitas, por exemplo.

"A estratégia mais importante foi ouvir os clientes, perceber o que as pessoas pesquisavam nas redes sociais, o que estavam a dizer, o que estavam a pesquisar e quais as categorias mais procuradas. As categorias mais procuradas foram as relacionadas com material de escritório, secretárias, organização da casa, frascos e caixas para acondicionar comida. Oferecemos o que as pessoas procuravam. Mostramos mais no nosso site gamas, artigos e soluções que as pessoas mais estavam a procurar e criamos conteúdos para melhorar a vida em casa, como decoradores a dar dicas nas redes sociais." Country Marketing Manager IKEA.

"Campanha promocional muito forte e envios gratuitos para todos os bens essenciais." Marketing, Growth \& Performance Team Leader Empresa Marketplace generalista.

“Tivemos de nos reinventar. No início da pandemia, disponibilizamos experiências gratuitas em casa, como forma de incentivar os portugueses a ficarem em casa e se entreterem de uma forma gratuita. Foi uma ação que funcionou muito bem e as pessoas valorizaram. Também alargamos a validade dos nossos vouchers, para o cliente, obviamente, ter mais tempo de usufruir das experiências." Diretora de Marketing e Comunicação Odisseias.

"Logo no início, o que fizemos foi entrega gratuita, o foco no serviço foi muito importante. Temos o cuidado de proporcionar a melhor experiência de compra, desde que o consumidor está connosco, no nosso site, temos uma equipa de user experience que vai afinando e fazendo a vigilância se estamos num bom 
caminho ou não. Tudo aqui anda há volta do serviço - entrega e prazos de devolução.” E-commerce Marketing Director La Redoute.

“A comunicação sofreu uma alteração imediata. Implementamos logo a estratégia de comunicação de crise, para fazer face a todos os constrangimentos que sabíamos que íamos ter até nos adaptarmos. Comunicamos, sobretudo, o esclarecimento. Primeiro, que estávamos a fazer melhorias para nos adaptarmos a toda esta situação, segundo, apoiar os clientes e estar próximo destes e disponíveis para os ouvir e continuar a apoiar e informar como todas as dinâmicas de e-commerce e onde as pessoas nos podiam encontrar e, terceiro, ao nível da responsabilidade social, no sentido de apoiar a estratégia social governamental e também criamos uma comunicação mais focada na vida das pessoas em casa e como podiam dinamizar o seu dia. Tentamos contribuir para que a nossa comunidade estivesse informada, confortável e tivesse a melhor experiência." E-commerce e Digital Marketing Manager Eugénio Campos.

\subsubsection{Desenvolvimento de parcerias durante o período pandémico}

Ao nível do desenvolvimento de parcerias no período pandémico, considera-se que foi bastante importante a nível empresarial e, realmente algumas empresas beneficiaram bastante destas. Aliás, algumas empresas admitem não ter criado parcerias, mas desenvolvido e melhorado as já existentes.

"Desenvolvemos parcerias muito importantes com associações de empresas, também para as ajudar. Começamos por fazer parcerias com feiras digitais, comunicar feiras que não eram possíveis de ser feitas presencialmente, como feiras de queijos, vinhos, do livro. Abrimos o nosso site como montra para essas feiras. Também realizamos uma parceria muito importante com o Grupo Sonae, no que toca à publicitação dos shoppings, como estes estavam fechados, trouxemos alguns players dos shoppings, lojas que tiveram a oportunidade de vender online no nosso site. Com o desenvolvimento de parcerias estratégias estamos a satisfazer duas necessidades, do lado dos sellers, a possibilidade de venderem imediatamente online para um público bastante alargado, uma vez que já temos a infraestrutura toda montada e de facto não têm possibilidade de ter uma ferramenta do dia para a noite onde possam vender online. Do nosso lado, oferecer ao cliente o que não estava disponível em outros sítios, não é em todo o lado que se encontra uma castanha de Sernancelhe, por exemplo. Nós 
temos essas coisas tradicionais e colmatamos essa necessidade do consumidor em encontrar esse tipo de produtos.” Marketing, Growth \& Performance Team Leader Empresa Marketplace generalista.

“Ao nível das parcerias, vamos sempre jogando com a altura do ano. Agora, no Dia do Pai, estamos a tentar ter parceiras para fazer uma coisa diferente. Criar sinergias entre marcas é muito importante, ainda por cima nesta fase, em que estamos a passar por situações complicadas, apoiar-nos uns aos outros é fundamental." Fundador The Florist.

"As parcerias que já tinham sido estrategicamente implementadas foram adaptadas e melhoradas e foi o suficiente para fazer face a toda a dinâmica." Ecommerce e Digital Marketing Manager Eugénio Campos.

\subsubsection{Diferenças percecionadas no consumidor}

Nesta fase pandémica, o consumidor viu-se privado de muitas das suas liberdades e, em alguns casos, a rotina mudou por completo e isto, inevitavelmente, reflete-se no que consome e na forma como o faz. Os entrevistados destacam, sobretudo, o novo à vontade com as compras online, o crescimento de determinadas categorias de produtos e o facto de os consumidores se tornarem mais exigentes.

"As pessoas têm necessidades novas e estão mais exigentes, querem tudo para hoje. A agilidade na entrega teve de ser muito maior." Country Marketing Manager IKEA.

"Além da parte do mercado e gourmet, algumas categorias cresceram, principalmente a das crianças, claramente, aquilo que os pais necessitavam para entreter as crianças cresceu exponencialmente. Conseguimos ser ágeis o suficiente para procurar mais sellers e lojas nesse sentido.” Marketing, Growth \& Performance Team Leader Empresa Marketplace generalista.

"Na restauração a diferença é brutal, as pessoas querem soluções mais digitais. Se há um ano atrás fossemos a um restaurante e víssemos um QR Code não sabíamos para que servia, hoje em dia, se não virmos $Q R$ Code, perguntamos para que serve o restaurante." CEO \& Co-Founder Pleez.

"Notaram-se diferenças na tipologia de produtos comprada. No início da pandemia, comprava-se muita roupa de conforto, de sportswear e lingerie, onde incluímos pijamas, cuecas, meias, etc. Outro mercado que cresceu muito foi o das crianças, os miúdos crescem, há uma necessidade muito grande. O 
mobiliário também cresceu muito, hoje em dia, 60\% das nossas vendas são feitas em cima do mobiliário, coisa que não se sucedia, é relativamente recente. Por sua vez, o calçado decresceu e até foi algo discutido com colegas de outros países e estava a acontecer o mesmo e faz sentido, como não podíamos sair ou andávamos com os mesmos ou com pantufas. Contudo, em 2021 já não verificamos o mesmo, não sei se é por estarmos mortinhos por voltar à vida normal e pôr os pés na rua." E-commerce Marketing Director La Redoute.

"No sentido de experiência de compra não há grande diferença. O apoio ao cliente foi mais intenso, exigiu mais de nós. Tivemos um maior cuidado e precaução na forma como transmitíamos informações aos clientes, porque as pessoas estavam mais sensiveis e stressadas e, da nossa parte, houve uma adaptação no sentido de mais paciência e proatividade com as pessoas. Aumentamos a informação que demos ao cliente nos diferentes pontos de contacto, um cliente informado tem expectativas adaptadas à realidade e está mais satisfeito. Também notamos uma maior procura pela área espiritual, ao que chamamos joias amuletos." E-commerce e Digital Marketing Manager Eugénio Campos.

\subsubsection{Criação de produtos e/ou serviços}

A pandemia Covid-19 levou a uma grande explosão de necessidades, o que se refletiu, em algumas empresas, na criação de produtos e serviços para colmatar essas mesmas necessidades e desejos. Algumas das empresas entrevistadas criaram/ofereceram novos produtos e desenvolveram serviços já existentes.

"Desenvolvemos muito o click and collect, era um serviço que já tínhamos ativo, mas não era muito usado e transformou-se num grande pilar de apoio ao negócio, as pessoas sentiam-se confortáveis e foi possivel satisfazer a necessidade de as pessoas terem as coisas rapidamente." Country Marketing Manager IKEA

"Conseguimos uma série de farmácias a vender no site, a área da saúde foi muito importante para nós. Também não tínhamos supermercados e minimercados e tivemos que trabalhar muito para os arranjar rápido. Complementamos o catálogo de criança, mais na ótica de brinquedos e de livros, com alfarrabistas tradicionais e algumas livrarias." Marketing, Growth \& Performance Team Leader Empresa Marketplace generalista. 
"Tivemos de nos reinventar. Oferecemos serviços possíveis de realizar em casa e começamos a oferecer produtos fisicos que se enquadrem no nosso propósito: fazer da vida uma verdadeira experiência." Diretora de Marketing e Comunicação Odisseias.

\subsubsection{Responsabilidade social corporativa}

A responsabilidade social corporativa é algo que as empresas têm vindo a apostar cada vez mais como partes integrantes da sociedade. Em tempos de pandemia, torna-se essencial a ligação entre as empresas e a sociedade, no sentido de se ajudarem mutuamente. Todas as empresas entrevistadas, consoante a sua possibilidade, demonstraram ter um papel bastante ativo a este nível.

"Faz parte de nós fazê-lo. Apoiamos hospitais com todos os pedidos que nos fizeram e enviamos kits criativos, com papeis, canetas e tintas que temos na nossa gama, para crianças com famílias sem disponibilidade financeira para comprar este tipo de produtos. O objetivo é que as crianças se tenham conseguido divertir e desenvolver a sua criatividade, num momento em que a escola estava fechada." Country Marketing Manager IKEA.

“Tivemos muito cuidado com o preço das máscaras. Começou a haver alguma especulação e nós tivemos esse cuidado, foi algo que quisemos evitar. Uma das grandes preocupações foi manter o mercado justo e viável.” Marketing, Growth \& Performance Team Leader Empresa Marketplace generalista.

"Fizemos uma campanha em que no Dia da Mãe fomos oferecer mil flores a mães no Hospital S. João que estavam a trabalhar e não conseguiram estar com os filhos. " Fundador The Florist.

"Desde o início da pandemia que tomamos medidas socialmente responsáveis, por exemplo, adquirimos material de proteção individual para doar a hospitais de Lisboa e Porto, compra de wakie talkies material para as crianças do Hospital de Estefânia, doação de 5.000€ à Cruz Vermelha Portuguesa e 10\% das nossas vendas também reverteram para a instituição." Diretora de Marketing e Comunicação Odisseias.

"Oferecemos uma refeição todas as semanas aos colegas da logística e é comprada especificamente nos restaurantes onde os nossos colegas iam com maior afluência, aqui, claramente, uma ajuda na restauração da zona. Existe uma série de restaurantes que estavam à volta deste entreposto de empresas e 
beneficiavam com as empresas à volta. No Natal, fizemos cabazes com produtos 100\% da região, há aqui um cuidado muito grande em termos de responsabilidade social. Também foi feito um contributo para um hospital." Ecommerce Marketing Director La Redoute.

“O primeiro passo foi a comunicação, no sentido de promover perante a nossa comunidade informações governamentais $e$ de incentivo à proteção $e$ cumprimento das regras estabelecidas e comunicação relacionada com a dinamização do dia-a-dia. Fizemos uma grande campanha com o Hospital S. João, em que criamos uma coleção de joias solidárias, em que cada venda daria lo€ ao hospital para a compra de bens necessários. Esta ação teve um grande impacto na comunidade e foi onde se refletiu mais o melhoramento da relação com a comunidade." E-commerce e Digital Marketing Manager Eugénio Campos.

\subsection{Discussão de resultados}

Ao nível das estratégias digitais para colmatar ou explorar os impactos da pandemia, destaca-se o desenvolvimento de parcerias, tanto na criação como no melhoramento das parcerias já existentes, o que é corroborado pelos estudos de Crick e Crick (2020) e Seetharaman (2020) e, para os autores, é um ponto vital para as empresas se manterem competitivas durante a pandemia; a criação de produtos/serviços contribuiu para satisfazer novos desejos e necessidades que surgiram durante a pandemia e comprova-se também no estudo de Kim (2020), que diz que as empresas se devem adaptar rapidamente para permanecerem visíveis, ágeis e produtivas; a adoção de medidas socialmente responsáveis está presente em todas as empresas inquiridas e demonstra-se nos estudos de Batista et al. (2020), Donthu e Gustafsson (2020), He e Harris (2020), Pantano et al. (2020) e Salvador e Ikeda, (2018).

As estratégias que obtiveram melhores resultados durante a pandemia, foram o foco no serviço e o foco no consumidor, o que também se verifica num guia lançado pelo Google chamado "5 approaches that are helping brands and peoople in Brazil during Covid-19" ("flexibilizar algumas condições, por exemplo, oferecer um horário mais alargado para pessoas de risco ou novas políticas de cancelamento de reservas"; “mudança de tom, adequando-se à pandemia, reforçando a ideia de que devemos evitar o contacto social, mas que nos podemos manter fortes e unidos neste momento"). Também, Vapiwala (2020), sugere que as organizações sejam autênticas, empáticas e 
sensíveis com os seus clientes, oferecendo suporte em tempos de crise e produtos ou serviços gratuitos, levando à criação de uma base de clientes fiéis.

\section{CONCLUSÕES E IMPLICAÇÕES}

A pandemia Covid-19 alterou, de facto, o comportamento de consumo e o ambiente empresarial, sendo as empresas obrigadas a adaptar-se a estas alterações para se manterem competitivas.

As empresas entrevistadas foram, claramente, afetadas, sobretudo, numa fase prematura, principalmente as relacionadas com serviços e turismo.

As redes sociais e o relacionamento no meio digital foram vistos como de extrema importância, sobretudo, pela proximidade, rapidez e visibilidade que oferecem.

Ao nível das estratégias digitais que obtiveram mais sucesso para colmatar/explorar os efeitos da pandemia, a maioria dos inquiridos demonstrou um grande foco no cliente, em tentar compreender o que este procurava e apoiá-lo, demonstrando que estávamos todos juntos numa fase tão atípica, disponibilizando produtos que as pessoas mais procuravam e desejavam no momento, criando conteúdos para a vida em casa e uma atitude mais tolerante e compreensiva para com o consumidor. Também se observou o foco no serviço, como entregas gratuitas, alargamento dos prazos de devolução, entre outros. Também, o desenvolvimento de parcerias, a criação de produtos e serviços e a adoção de medidas socialmente responsáveis também se mostraram relevantes, para a criação de sinergias e de valor.

A relevância deste estudo, centra-se, na compreensão de como as empresas reagem a uma crise sem precedentes, tendo de lidar com uma situação de extrema imprevisibilidade, alterando a sua forma de atuação e, por vezes, até a forma como criam valor e, ao mesmo tempo, compreender um novo consumidor que nasce num período tão conturbado, onde impera o medo, a incerteza e a falta de informações. Em suma, esta crise oferece uma excelente oportunidade para os profissionais de marketing, examinarem a interação entre fatores pessoais e contextuais.

Para além disto, também é indiscutível a importância do estudo para a gestão, ao nível da adoção das melhores estratégias para fazer face a períodos tão atípicos e conturbados como o da pandemia Covid-19.

Considera-se que se atingiram todos os objetivos propostos, contudo, o contexto pandémico dificultou a recolha de dados, na medida em que se optou por entrevistas 
remotas, sendo mais difícil compreender a linguagem não verbal.

\subsection{Limitações}

As principais limitações deste estudo são a sua natureza qualitativa que impossibilita a generalização de dados e o estado da arte, pela recentidade do tema. Quanto à recolha de dados, o facto de terem sido entrevistas não presenciais, diminuiu o impacto e a compreensão da linguagem não verbal.

\subsection{Investigação futura}

No que diz respeito à investigação futura, considera-se interessante realizar o estudo em profundidade e em categorias de produtos específicas, de forma a avaliar as estratégias digitais mais relevantes para determinados setores de atividade.

\section{REFERÊNCIAS}

Bardin, L. (2011). Análise de conteúdo. Lisboa: Edições 70.

Barreto, M., Barros, A., Carvalho, M., Codeço, C., Hallal, P., Medronho, R, Struchiner C., Victoria C. \& Werneck G. (2020). O que é urgente e necessário para subsidiar as políticas de enfrentamento da pandemia de COVID-19 no Brasil? Revista Brasileira de Epidemiologia, 23.

Batista, K., Saran, A. P. M., Limongi, R., da Silva, A. L. B., \& Gomes, A. C. (2020). Comunicação organizacional nas mídias sociais em temos de COVID-19. Gestão e Sociedade, 14(39), 3689-3697.

Bryman, A., \& Bell, E. (2011). Business Research Methods. Oxford University Press. Castro, B., Oliveira, J., Morais, L. \& Gai, M. (2020). COVID-19 e organizações: estratégias de enfrentamento para redução de impactos. Revista Psicologia Organizações e Trabalho, 20(3), 1059-1063.

Creswell, J. (2015). 30 essential skills for the qualitative researcher. Los Angeles, CA: SAGE.

Crick, J. \& Crick, D. (2020). Coopetition and COVID-19: Collaborative business-to business marketing strategies in a pandemic crisis. Industrial Marketing Management, 88, 206-213.

Croda, J., Oliveira, W., Frutuoso, R., Mandetta, L., Baia-da-Silva, D., Brito-Sousa, J., Monteiro W. \& Lacerda M. (2020). COVID-19 in Brazil: advantages of a socializedunified health system and preparation to contain cases. Revista da Sociedade Brasileira de Medicina Tropical, 53: e20200167.

Dias, M. O. (2009). O vocabulário do desenho de investigação. A lógica do processo em ciências sociais. Viseu: Psicosoma.

Donthu, N., \& Gustafsson, A. (2020). Effects of COVID-19 on business and research. Journal of Business Research, 117, 284-289.

Dwivedi, Y., Hughes, D., Coombs, C., Constantiou, I., Duan, Y., Edwards, J., Gupta, B., Lal, B., Misra, S., Prashant, P., Raman, R., Rana, N., Sharma, S. \& Upadhyay N. (2020). Impact of COVID-19 pandemic on information management research and 
practice: Transforming education, work and life. International Journal of Information Management, 55, 102211.

Euronews (2020). Execução económica "pior" do que as projeções do FMI. https://pt.euronews.com/2020/05/12/execucao-economica-pior-do-que-as-projecoesdo-fmi on 28 july, 2021.

Flick, U. (2005). Métodos qualitativos na investigação científica. Lisboa, Monitor.

Kim, R.(2020). The Impact of COVID-19 on Consumers: Preparing for Digital Sales. IEEE Engineering Management Review, 48, 212 - 218.

Kodama, M. (2020). Digitally transforming work styles in an era of infectious disease. International Journal of Information Management, 55. 102172.

Kohli, S., Timelin, B., Fabius, V. \& Veranen, S. (2020). How COVID-19 is changing consumer behavior-now and forever. McKinsey \& Company.

Guest, G., Bunce, A., \& Johnson, L. (2006). How many interviews are enough? An experiment with data saturation and variability. Field methods, 18(1).

He, H., \& Harris, L. (2020). The Impact of Covid-19 Pandemic on Corporate Social Responsibility and Marketing Philosophy. Journal of Business Research, 116, 176182.

Outmarketing (2020). Marketing Digital em Tempos de Pandemia. https://digital.outmarketing.pt/ebook-marketing-digital-em-tempos-depandemia?rdst_srcid $=2135593$ on 5 august, 2021.

Panigutti, C., Perotti, A., \& Pedreschi, D. (2020). Doctor XAI: An ontology-based approach to black-box sequential data classification explanations. Paper presented at the 2020 Conference on fairness, accountability, and transparency, Barcelona.

Pantano, E., Pizzi, G., Scarpi, D., \& Dennis, C. (2020). Competing during a pandemic? Retailers' ups and downs during the COVID-19 outbreak. Journal of Business Research, 116, 209-213.

Salvador, A. \& Ikeda, A. (2018). Brand crisis management: the use of information for prevention, identification and management. Brazilian Business Management Magazine, 20(1), 74-91.

Seetharaman, P. (2020). Business models shifts: Impact of Covid-19. International Journal of Information Management, 54, 102173.

Silverman (2011). Interpreting Qualitative Data: A Guide to the Principles of Qualitative Research(fourth ed.), Sage, London (2011)

Shiffman, J., \& Shawar, Y. R. (2020). Strengthening accountability of the global health metrics enterprise. Lancet, 395, 1452-1456.

Sousa, M. J., \& Baptista, C. S. (2011). Fazer investigação, dissertações, teses e relatórios segundo bolonha. Lisboa: Pactor,

Stewart, D. (2021). Uncertainty and risk are multidimensional: Lessons from the COVID-19 pandemic. Journal of Public Policy \& Marketing, 40(1), 97-98.

Think With Google. (2020). 5 approaches that are helping brands and people in Brazil during COVID-19. https://www.thinkwithgoogle.com/intl/ptbr/tendencias-deconsumo/5-abordagens-que-estao-ajudandomarcas-e-pessoas-no-brasil-durante-acovid- on 7 august, 2021.

Vapiwala, F. (2020). Digital Marketing-A Saviour for Businesses in Times of a Pandemic. International Journal of Research in Engineering, Science and Management, 3(9), 159-161.

Verma, S., \& Gustafsson, A. (2020). Investigating the emerging COVID-19 research 
trends in the field of business and management: A bibliometric analysis approach. Journal of Business Research, 118, 253-261.

Winston, A., (2020). Is the COVID-19 Outbreak a Black Swan or the New Normal? https://sloanreview.mit.edu/article/is-the-covid-19-outbreak-a-black-swan-or-thenew-normal/ on 2 august, 2021.

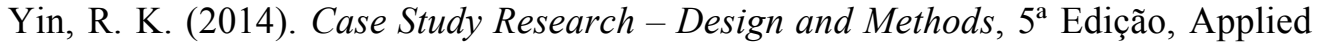
Social Research Methods Series, Los Angeles: Sage Publications.

\section{How to cite this article:}

Santos, J. \& Lima, A. P. (2022). Estratégias Digitais de Combate aos Impactos da Pandemia Covid-19 no Contexto Empresarial, International Journal of Marketing, Communication and New Media. Special Issue on Marketing in the Context of COVID-19, January 2022, 92-113. 